\title{
The role of free endosomal epitopes in the mechanisms of amelioration and flares of rheumatoid arthritis-associated conditions: pregnancy and infective hepatitis
}

Innocenzo Caruso ${ }^{1 *}$ DD, Enzo Massimo Caruso ${ }^{2}$, Salvatore Santandrea ${ }^{1}$, Franco Montrone ${ }^{3}$, Piercarlo Sarzi Puttini ${ }^{1}$ and Marco Cazzola ${ }^{4}$

\begin{abstract}
Background: It is known that rheumatoid symptoms improve in pregnancy and in patients who develop infective jaundice. The mechanism of amelioration might involve the direct interaction of free endosomal self-epitopes that are released by the cells of the involved organ with antigen binding sites on the membranes of anti-idiotypic cells, resulting in possible suppressive effects.

Methods: Immune responses of peripheral blood mononuclear cells (PBMCS) to longstanding synovial fluid (SFMC or primary ultrafiltrate) and to the endosomal extracts enriched with self-epitope-receptor microcomplexes (MICs) were investigated. The MICs (secondary ultrafiltrate) were prepared from PBMCs that were previously cultured with SFMC ultrafiltrates and had therefore been in contact with large number of self-epitopes.

Results: Addition of primary ultrafiltrate to PBMCs elicited significant expansion of regulatory $T$ cells (CTLA-4+CD4 + CD25+), and reduction of CD69+CD4+CD25+ cells. In contrast, secondary ultrafiltrate, which contains the microcomplexes, produced an inflammatory response, with CD69+ cells increasing to 47\% of CD4+CD25+ cells. This opposite response indicated that, in all likelihood, the response of mononuclear cells to secondary ultrafiltrate in culture involved a subset of CD4+ T cells other than those of the primary ultrafiltrate.

Conclusions: Free endosomal epitopes, released from the maternal-fetal interface and necrotic areas of diseased liver, inducing expansion of regulatory $T$ cells, provided a type of endogenous, autonomic immunotherapy. The post-partum flare-up of the disease could be due to the sudden interruption of endogenous immunotherapy at delivery and to the inflammatory response to microcomplexes that are recognized by autoreactive $T$ cells.
\end{abstract}

Keywords: Longstanding synovial fluid, Endosomal autoantigen, Endogenous immunotherapy, Self-epitope-receptor microcomplexes, Ultrafiltrates, Primary and secondary

\section{Background}

Rheumatoid arthritis (RA) symptoms are known to improve in pregnant women. A recent report found that almost half of pregnant RA patients experienced symptom improvement during pregnancy, especially during the third trimester, and more than one-third had a flare-up of the disease after delivery [1]. Improvement of RA

\footnotetext{
* Correspondence: innocenzo.caruso@tiscali.it

${ }^{1}$ Rheumatology Unit, L. Sacco Hospital Milan Italy, Corso Italia 11, 20122

Milano, Italy

Full list of author information is available at the end of the article
}

symptoms in patients with hepatocellular jaundice was described for the first time toward the end of the nineteenth century. In a clinical trial in 1945, investigators attempted to inoculate volunteer arthritic patients with icterogenic serum to induce jaundice. Ten of 32 patients who developed jaundice went into remission for a short time, and 15 reported temporary improvement. The mean duration of improvement was 42 days [2]. The hypothesis that we present here is that hepatitis and pregnancy are two conditions in RA patients in which the undefined pathogenic epitopes of the basic systemic 
disease are released from endosomal compartments of the cells of the involved organ.

Endosomal autoantigens that are taken up and transported by macrophages and dendritic cells are spread to all lymphoid organs and synovial membranes. There, they induce the expansion of the regulatory $\mathrm{T}$ cell (TREG cell) population, thereby exerting suppressive action [3-5] and contributing to the amelioration of RA.

The mechanism of RA amelioration might involve the direct interaction of self-epitopes that are not associated with class II major histocompatibility complex molecules, with the antigen-binding sites on the membranes of anti-idiotypic cells.

The same mechanism may have been iatrogenically triggered when rifamycin SV, an antibiotic with marked cytolytic properties, was injected in joints. The good therapeutic response in patients with arthritides [6, 7], confirmed in a recent retrospective work [8], was due to the expulsion of endosomal bioactive peptides from synovial membrane cells.

Taken together, these data suggest a mechanism of endogenous, antigen-specific, autonomic immunotherapy that persists at least for the duration of epitope leakage.

We tested this hypothesis in an experimental in vitro model, in which the suppressive activity of the ultrafiltrate of longstanding synovial fluid (SFMC or primary ultrafiltrate), containing a large amount of self-epitopes, on rheumatoid peripheral blood mononuclear cells (PBMCs) in culture was measured as an increase in TREG cell expression. In addition, the ability of ultrafiltrates that had been enriched in pathogenetic epitopes (secondary ultrafiltrate or SFMC-PBMC) to change the immune response of mononuclear cells in culture was investigated. The secondary ultrafiltrate was prepared from PBMCs that were previously cultured with SFMC ultrafiltrate and had therefore been in contact with large number of self-epitopes.

\section{Methods}

The in vitro model with which we studied the immune response of rheumatoid $\mathrm{CD} 4 \mathrm{~T}$ cells to the different ultrafiltrates is shown in Fig. 1.

In step n.1, the effects of SFMC ultrafiltrate (longstanding synovial fluid) on the expression of CD69 + and CTLA-4 by mononuclear cells in culture were tested.

In step n.2, the effects of the two secondary ultrafiltrates, SFMC-PBMC ultrafiltrate and medium-PBMC ultrafiltrate, on the expression of the same cell markers were compared.

\section{Ultrafiltrates}

Our strategy to extract and identify the pathogenic epitopes was linked to the notion that in a systemic disease such as RA, the arthritogenic epitope would be present in all antigen-presenting cells (APCs), including circulating cells, as well as in synovial cells.

The endosomal epitopes released following the inflammatory lysis of synoviocytes accumulate freely, along with many other unknown peptides in synovial fluid.

\section{Preparation of primary ultrafiltrate from PBMCs}

PBMCs were thawed or harvested, centrifuged at $350 \times g$ for $10 \mathrm{~min}$, washed three times with phosphate-buffered saline (PBS), and resuspended at $1-5 \times 10^{6}$ cells per $\mathrm{ml}$ in Dulbecco's PBS (DPBS; Carlo Erba, C Dasit group, Milan, Italy). The cells were subjected to three freeze-thaw cycles from $-80^{\circ} \mathrm{C}$ to room temperature and were centrifuged at $1,500 \times g$ for 10 minutes. Ultrafiltrates were prepared by passage through Millipore filtration devices with a 10,000 Da molecular weight cut-off (Millipore, Bedford, MA, USA) and stored at $-20^{\circ} \mathrm{C}$ until required.

\section{Preparation of primary ultrafiltrate from synovial fluid (SFMC)}

The synovial fluid samples were centrifuged at 400xg for 15 minutes; the supernatant was then ultrafiltered as above and stored at $-20^{\circ} \mathrm{C}$ until use.

\section{Preparation of secondary ultrafiltrates}

Two types of secondary ultrafiltrate were prepared: from PBMCs cultured with SFMC, in which the cells remain in contact with large number of self-epitopes (SFMCPBMC ultrafiltrate), and from PBMCs cultured with ultrafiltrates derived from PBMCs grown in culture medium (medium-PBMC ultrafiltrate). In the case of SFMC ultrafiltrates, a micro-BCA protein assay (Pierce) was performed to determine the protein concentrations (see below).

The PBMC ultrafiltrates were adjusted to $10 \%$ human $\mathrm{AB}$ serum prior to addition to the cell cultures. The ultrafiltrate from a normal donor was not toxic to normal PBMCs. The toxicity was assayed in cell culture in which the effects of increasing volumes of SFMC were evaluated by the percentage of CD69 expression (\%CD69/CD3). Therefore, the maximum feasible amount of ultrafiltrate $(0.1 \mathrm{mg}$ protein $/ 200 \mu \mathrm{l})$ was used.

\section{Cells}

The cells used for cultures were obtained from a pool of approximately $50 \mathrm{ml}$ of whole blood, drawn from 6 patients with active rheumatoid disease. PBMCs were purified on a Ficoll Hypaque gradient using standard techniques. The cells were frozen in aliquots of $5-10 \times 10^{6}$ cells per $\mathrm{ml}$ and stored in a cryogen tank until use. 


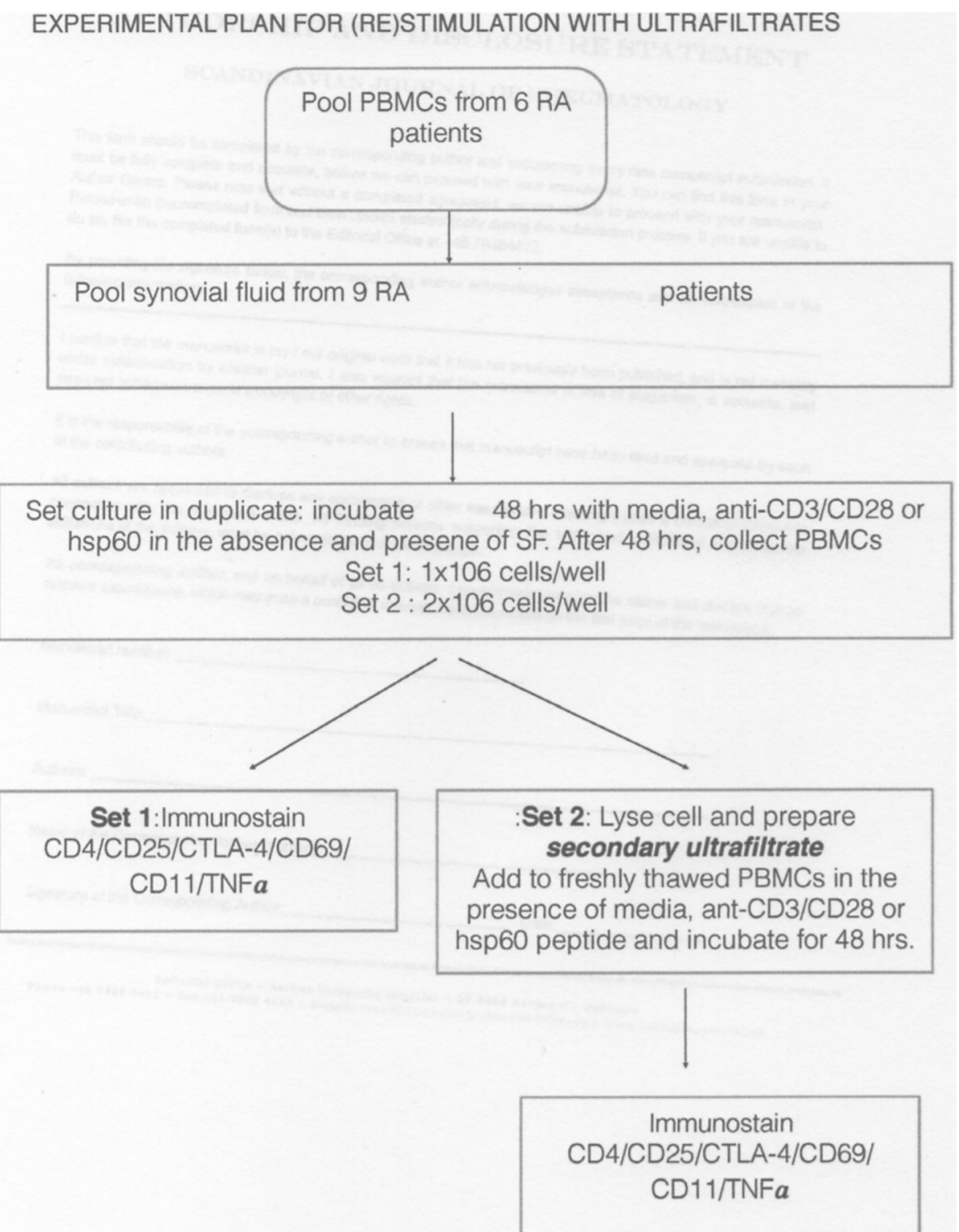

Fig. 1 Experimental plan for (re)stimulation with ultrafiltrates

\section{Synovial fluid}

The synovial fluid samples from 9 RA patients were stored at $-20^{\circ} \mathrm{C}$ until use and then thawed and pooled in the laboratory for in vitro assays.

\section{Media}

The medium consisted of RPMI 1640 supplemented with $10 \%$ heat-inactivated human $\mathrm{AB}$ serum (Gemini Scientific, $100 \mathrm{U} / \mathrm{ml}$ penicillin, $100 \mu \mathrm{g}$ streptomycin and $1 \mathrm{mM}$ glutamine).

\section{Cell stimulation}

PBMCs were cultured in duplicate for 48 hours with medium alone, with $5 \mu \mathrm{g} / \mathrm{ml}$ plastic bound anti-CD3 and
$2 \mu \mathrm{g} / \mathrm{ml}$ soluble anti-CD28, or with $10 \mu \mathrm{g} / \mathrm{ml}$ peptide, consisting of tetanus toxoid (QYIKANSKFIGITEO) or hsp60 (GEALSTLVVNKIRGT). Ultrafiltrate was then added to one set of cultures.

\section{Immunostaining}

Immunostaining was used to measure 1) TNF $\alpha$ production by $\mathrm{T}$ cells and macrophages; 2) CD69 as an indicator of cell proliferation; and 3) CTLA-4 expression by CD4+ cells, and more specifically by CD4+/CD25+ cells. CTLA-4+ transmits signals that inhibit $\mathrm{T}$ cell activation. As an inhibitor of $\mathrm{T}$ cell function, it is not expressed by resting $\mathrm{T}$ cells. The number of circulating TREG cells in RA patients has been the subject of numerous studies, 
however, the results have been extremely discordant because of differences in the classification criteria for these cells, as reported by a recent systematic review [9]. However, CTLA-4, CD25 and FOXP3 continue to be widely used as molecular markers of activated TREG cells that play an essential role in immune regulation and $\mathrm{T}$ cellmediated suppression.

\section{Statistical analysis}

Nonspecific staining, as determined with the isotype controls, was subtracted (as a percentage) from the positive responses. Differences between matched, untreated PBMCs and samples treated with ultrafiltrate were analyzed by Wilcoxon's paired rank test.

\section{Results}

\section{The effects of synovial fluid ultrafiltrate on PBMCs in culture}

The addition of SFMC ultrafiltrate to rheumatoid PBMC cultures elicited significant expansion $(p=0.05,+70 \%)$ of TREG cells (\%CTLA-4/CD4+CD25+) (Fig. 2), while in cultures from normal subjects, the percentage of CTLA4 decreased by $34 \%$. These results strongly suggested that the primary ultrafiltrate exerted an immune regulatory action on PBMCs in culture. The suppressive action was supported by the results concerning the expression of CD69 (\%CD69/CD4+DC25+) by the same cell population, which was significantly decreased $(p=0.04,-72 \%)$. The addition of the ultrafiltrate never elicited a proinflammatory response (TNF $\alpha, \mathrm{CD} 11 \mathrm{c})$.

The effects of secondary ultrafiltrates on PBMCs in culture In the experimental plan outlined in Fig. 1, step 2, PBMCs harvested from the same 6 rheumatoid patients receiving the same treatments (media alone, CD3 and

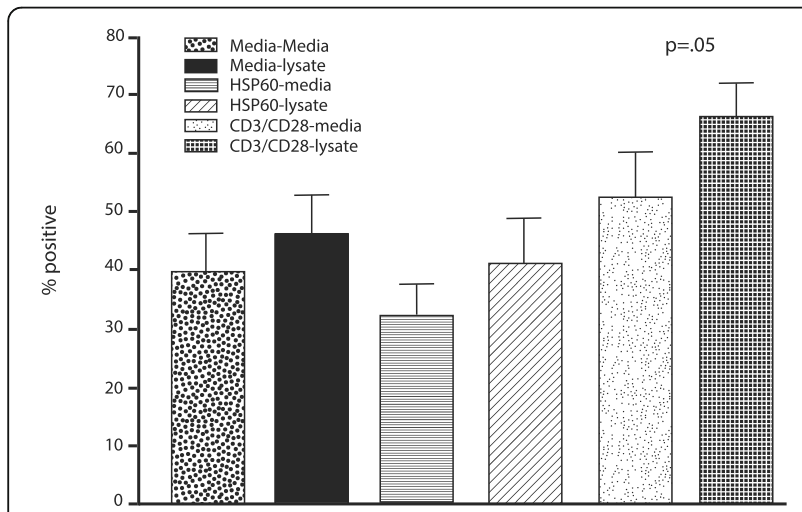

Fig. 2 Expression of CTLA-4 by CD4+CD25+ cells from six ra patients. Results are shown as mean and standard deviation. CTLA-4 increased slightly despite the decrease in CD69 expression (not shown) and was significant in the case of the CD4+CD25+ T cells following the addition of primary ultrafiltrate (From Caruso I et al J Transl Med (2016) 14:162)
CD28 antibodies or hsp60 peptide) were all cultured with corresponding secondary ultrafiltrate derived from stimulated PBMCs in media (-) or in SFMC filtrate (+). After 48 hours, the cells were harvested and immunostained.

No statistically significant differences were observed between the medium-PBMC ultrafiltrate $(200 \mu \mathrm{l})$ and the SFMC-PBMC ultrafiltrate $(100 \mu \mathrm{g} /$ well $(200 \mu \mathrm{l})$.

In all cases, there was an increase in both CD69 and CTLA-4, but the highest values were reached by the former. In particular, CD69 expression was increased by $5 \%$ and $13.1 \%$ in CD4+ cells and CD4+CD25+ cells, respectively, with the addition of secondary media/PBMC ultrafiltrate, while increases of $33 \%$ and $47 \%$ were observed with the addition of SFMC-PBMC ultrafiltrate (Fig. 3).

The notable expansion in the expression of CD69 in the latter cultures suggested the hypothesis that a subset of cells, different from those stimulated by longstanding synovial fluid, had been triggered by a specific bioactive peptide that was contained exclusively in the SFMCPBMC ultrafiltrate.

\section{Discussion}

The local enrichment of natural TREG cells in the uterine decidua and the secretion of cytokines that activate immune mechanisms that protect the fetus from rejection by the maternal immune system are not involved in the modification of the underlying RA. This is because they have specificity for the paternal fetal antigen [10]. Therefore, the amelioration of clinical RA symptoms in pregnancy is not an additional or collateral effect of the immunoregulatory response that prevents rejection of a genetically distinct fetus [11-13], but rather it is a specific, independent immune response. According to our hypothesis, one of the many unknown antigens contained in the endosomal compartment that is released

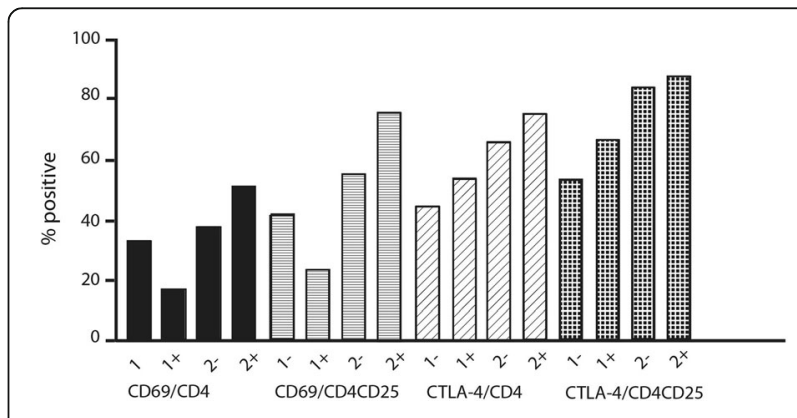

Fig. 3 A summary of the effect of primary and secondary ultrafiltrates on expression of CD69 and CTLA-4 by T cells stimulated with anti-CD3/ CD28. The - indicates media (1=primary) or secondary ultrafiltrate (2) generated from media treated cells while + indicates synovial fluid ultrafiltrate (1) or secondary ultrafiltrate generated from synovial fluid ultrafiltrate treated cells (2) 
following the lysis of the proliferating mononuclear cells in the areas where the fetal-derived trophoblast cells penetrate the uterine tissue mediates the effects of pregnancy via its ability to activate an immune-suppressive response.

Similarly, TREG cells specific to a pancreatic islet autoantigen offered protection against type 1 diabetes [14].

The number of self-epitopes released from the maternal-fetal interface increases with the increase in decidua surface and consequently also enhances the global immune-suppressive response. This mechanism could help to explain the increase in improvements that occur during the third trimester of pregnancy.

The results of our study on immune response in RA patients support the hypothesis that endogenous bioactive peptides may play clinically significant roles both in pathophysiological and in pathological conditions.

The immune-suppressive response of PBMCs in culture to the addition of rheumatoid primary ultrafiltrate indicates the involvement of a specific antigen that triggers cells (in subjects) that have the basic immunological memory of pathogenic antigens. The expansion of TREG cells is even more meaningful when considering that mononuclear cells were stimulated with anti-CD3/CD28. These epitopes do not appear to be present in cells from normal subjects when the primary ultrafiltrate was prepared by freeze/thawing of PBMCs.

The results of our study on immune response of rheumatoid PBMC in cultures provide a reasonable explanation of impaired mixed lymphocyte reaction [15] which could be connected with the presence of pathogenic endosomal epitopes released by the APCs of the two rheumatoid cell populations used for this test.

Another considerable piece of support for these mechanisms of amelioration was provided by the positive therapeutic results obtained by subcutaneous injection of rheumatoid arthritis patients with both SFMC ultrafiltrate and primary medium-PBMC ultrafiltrate [16]. The former was much more effective than the latter.

The same pathogenic antigens, in this case released from necrotic cells of the livers of rheumatoid arthritis patients with infectious hepatitis, increased an immune-suppressive response in joints and all inflamed areas.

Considering the second step of the study (Fig. 1), our results demonstrated that, in contrast to the immuneregulation response that we observed in cell cultures exposed to primary ultrafiltrate (containing free endosomal epitopes), an inflammatory response with an increase of CD69 occurred with secondary ultrafiltrate. This is the earliest inducible cell surface activation marker that is involved in lymphocyte proliferation.

The opposite results for expression of CD4+CD69+ $(+47 \%)$ indicated that, in all likelihood, the response to secondary ultrafiltrate in culture involved a subset of CD4+ $\mathrm{T}$ cells other than those of the primary ultrafiltrate.

A possible explanation for the change in the immune responses of PBMCs in culture could be found by examining the various steps in the preparation of the secondary ultrafiltrates. During cell culture, epitopes contained in primary ultrafiltrates adhered to receptors and formed intermolecular connections on mononuclear cell membranes. The subsequent fragmentation of cells by freezing/thawing caused detachment in the form of selfepitope-receptor microcomplexes, which, when added to PBMC cultures, triggered an immune effector mechanism other than that of TREG cells.

Similar to the in vitro results, the inflammatory disruption of the mononuclear cells could favor the formation of microcomplexes that activate autoreactive $\mathrm{T}$ lymphocytes via $\mathrm{T}$ cell receptors, resulting in amplification of the inflammatory immune response. According to this hypothesis, the post-partum flare-up of the disease could be due to the sudden interruption of endogenous immunotherapy at delivery, after a period of 8 months or longer of gestation, and to the inflammatory response to microcomplexes released once the suppressive activity of free epitopes (from the decidua) is reduced.

Although microparticles have been described in systemic lupus erythematous $[17,18]$, they appear to be unrelated to the microcomplexes described herein because they are too large $(0.1-1.0 \mu \mathrm{m})$ to pass through $10 \mathrm{kDa}$ cut-off ultrafilters.

Finally, in rheumatoid arthritis patients, self-epitopereceptor microcomplexes and pathogenic epitopes accumulate in the synovial fluid and in all the inflamed areas where both immunoregulatory and pro-inflammatory mechanisms could be active during all phases of RA. The former would prevail when endosomal pathogenic epitopes are abundant (particularly in the last stage of pregnancy, when they increase further). The latter, which activates autoreactive $\mathrm{T}$ lymphocytes, predominates when large numbers of molecular peptidic microcomplexes are present.

One limitation of this study was that none of the patients were affected by any of the aforementioned associated clinical conditions. We believe that this limitation might be overcome by the TREG cells always and specifically responding to the pathogenic epitopes of the underlying disease in the absence and the presence of pregnancy and infective hepatitis.

In addition, if other $\mathrm{T}$ cell subsets contribute to suppressive action, the results are not invalidated, because the aim of the study was to demonstrate the presence of undefined free autoantigens through this type of response by rheumatoid mononuclear cells in culture. 
This study could help to define the range of the field when searching for a common denominator of these two conditions that can occur during the course of arthritis, pregnancy and infectious hepatitis, as advocated by PS Hench in 1938 [19].

\section{Conclusions}

Amelioration of RA symptoms, as seen in pregnancy or hepatocellular jaundice, can be attributed to release of self-epitopes inducing expansion of TREG cells, providing an endogenous, antigen-specific autonomic immunotherapy. In the former condition, the epitopes are released from the maternal-fetal interface. In the latter, they are released by necrotic areas of diseased liver. Given the systemic nature of this disease, these pathogenic epitopes are found in all antigen presenting cells.

The flare-up of disease could be due to the sudden interruption of endogenous immunotherapy at delivery, after a period of 8 months or longer of gestation and to the inflammatory response to self-epitope-receptor microcomplexes that are recognized by autoreactive $\mathrm{T}$ cells.

The results of this study could help to define the range of the field when searching for the common denominator of these two conditions (pregnancy and infective hepatitis) that occur during the course of rheumatoid arthritis. Furthermore, they may stimulate research into the possible gradual development of a type of autonomic endogenous immunotherapy for patients affected by diseases (not primarily autoimmune) who develop immunity to unknown epitopes produced by necrotic processes.

\section{Abbreviations}

PBMC: Peripheral blood mononuclear cell; TREG: Regulatory T call; APC: Antigen presenting cell; RA: Rheumatoid arthritis; SFMC: Longstanding synovial fluid; SFMC-PBMC: Secondary ultrafiltrate

\section{Acknowledgments}

We would like to thank Elissa Keogh and Angela Min, MD (Clinical Investigation Institute. University of California, San Diego) for assistance in laboratory assays.

\section{Funding}

No funding to declare.

\section{Availability of data and materials}

Not applicable.

\section{Authors' contributions}

Study conception and design, Cl. Acquisition of data, MF, CEM, CM. Analysis and interpretation of data, CI, SPP, SS. All authors read and approved the final manuscript to be published

\section{Ethics approval and consent to participate}

The study design was approved by the Ethics Committee of L. Sacco Hospital and by the Ethics Committee of the Regional Government of Lombardy, Italy. deliberation N.599 (July 30,2009). The ethics committee reviewed the study prior to enrollment of patients. Informed consent was obtained from all participating patients.

\section{Consent for publication}

Not applicable.

\section{Competing interests}

The authors declare that they have no competing interests.

\section{Publisher's Note}

Springer Nature remains neutral with regard to jurisdictional claims in published maps and institutional affiliations.

\section{Author details}

${ }^{1}$ Rheumatology Unit, L. Sacco Hospital Milan Italy, Corso Italia 11, 20122 Milano, Italy. ${ }^{2}$ Orthopedic Unit, ist. Clinico San Siro, Milan, Italy. ${ }^{3}$ Associazione Italiana, Contro I'Artrite (AICA), Milan, Italy. ${ }^{4}$ Rehabilitation Department, Saronno Hospital, Varese, Italy.

Received: 25 January 2018 Accepted: 26 February 2018

Published online: 27 March 2018

\section{References}

1. de Man YA, Dolhain RJ, van de Geijn FE, Willemsen SP, Hazes JM. Disease activity of rheumatoid arthritis during pregnancy: results from a nationwide prospective study. Arthritis Rheum. 2008;59:1241-8.

2. Gardner F, Stewart A, Mac Callum FO. Therapeutic effect of induced Jaundice in rheumatoid arthritis. Brit Med J. 1945;17(2):677-80.

3. Jerne NK. The immune system. Sci Am. 1973;229:52-60.

4. Hoffmann GW. A network theory of the immune system. Eur. J. Immunol. 1975:5(9):638-47. https://doi.org/10.1002/eji.1830050912.

5. Corthay A. How do regulatory T cells work? Scand J Immunol. 2009;70(4): 326-36. https://doi.org/10.1111/j.1365-3083.2009.02308.

6. Caruso I, Montrone F, Fumagalli M, Patrono C, Santandrea S, Gandini M. Rheumatoid knee synovitis successfully treated with intra-articular Rifamycin SV. Ann Rheum Dis. 1982:41:232-6.

7. Caruso I, Principi N, D'Urbino G, Santandrea S, Boccassini L, Montrone F, Sarzi Puttini PC, Bombaci A, Bozzato A, Azzolini V, Dell'Acqua D. Rifamycin SV administered by intra-articular infiltrations shows disease modifying activity in patients with pauici and polyarticular juvenile rheumatoid arthritis. J Int Med Res. 1993;21:243-56.

8. Caruso I, Cazzola M, Santandrea S, Caruso EM, Montrone F. Rifamycin SV intrasiniovally injected in arthritides patients showed anti-synovitis activity and some features of the disease modifying drug. SM Chronic Dis. 2017;1(1):1001.

9. Morita T, Shima Y, Badger JW, Shimon Sakaguchi S, Ogata A, Kumanogoh A. The proportion of regulatory $T$ cells in patients with rheumatoid arthritis: a meta-analysis. PLoS One 2016;11, https://doi.org/10.1371/journal.pone. 0162306

10. Kahna DA, Baltimoreb DB. Pregnancy induces a fetal antigen-specific maternal T regulatory cell response that contributes to tolerance. Proc Natl Acad Sci USA. 2010;107:9299-304.

11. Munoz-Valle JF, Vazquez-Del Mercado M, Garcialglesias T. T(H)1/T(H)2 cytokine profile, metalloprotease- 9 activity and hormonal status in pregnant rheumatoid arthritis and systemic lupus erythematosus patients. Clin Exp Immunol. 2003;131:377-84.

12. Förger F, Marcoli N, Gadola S, Möller B, Villiger PM, Østensen M. Pregnancy induces numerical and functional changes of CD4+CD25high regulatory $T$ cells in patients with rheumatoid arthritis. Ann Rheum Dis. 2008;67:984-90. https://doi.org/10.1136/ard.2007.075283.

13. Østensen M, Villiger PM, Förger F. Autoimmun Rev. 2012 May;11(6-7): A437-46. doi: 10.1016/j.autrev.2011.11.013. Epub 2011 Dec 2. Interaction of pregnancy and autoimmune rheumatic disease. Autoimmun Rev. 2012;11(6-7):A437-46. https://doi.org/10.1016/j.autrev.2011.11.013. Epub 2 Dec 2011

14. Tarbell KV, Yamazaki S, Olson K, Toy P, Steinman RM. CD25 + CD4 + T cells, expanded with dendritic cells presenting a single autoantigenic peptide, suppress autoimmune diabetes. J Exp Med. 2004;199:1467-77.

15. Astorga GP, Williams RC Jr. Altered reactivity in mixed lymphocyte culture of lymphocytes from patients with rheumatoid arthritis. Arthr. Rheum. 1969:12:257.

16. Caruso I, Santandrea S, Gismondo M, Lombardi A, Montrone F, Caruso EM, et al. Vaccination with endosomal unknown epitopes produces therapeutic response in rheumatoid arthritis patients and modulates adjuvant arthritis of rats. J Transl Med. 2016;14:162-76. https://doi.org/ 10.1186/s12967-016-0908-7. 
17. Mobarrez F, Vikerfors A, Gustafsson JT, Gunnarsson I, Zickert A, Larsson A, Pisetsky DS, Wallén $H$, Svenungsson E. Microparticles in the blood of patients with systemic lupus erythematosus (SLE): phenotypic characterization and clinical associations. Sci Rep. 2016;6:36025. https://doi.org/10.1038/srep36025.

18. Wu H, Siqi F, Zhao M, Lu L, Qianjin L. Dysregulation of cell death and its epigenetic mechanisms in systemic lupus erythematosus. Molecules. 2017; 22(1):30. https://doi.org/10.3390/molecules22010030.

19. Hench PS. The ameliorating effect of pregnancy on chronic atrophic (infectious rheumatoid) arthritis, fibrositis, and intermittent hydrarthrosis. Mayo Clin Proc. 1938;13:161-77.

Submit your next manuscript to BioMed Central and we will help you at every step:

- We accept pre-submission inquiries

- Our selector tool helps you to find the most relevant journal

- We provide round the clock customer support

- Convenient online submission

- Thorough peer review

- Inclusion in PubMed and all major indexing services

- Maximum visibility for your research

Submit your manuscript at www.biomedcentral.com/submit
Biomed Central 